OPEN ACCESS

Edited by:

Jayashri Kulkarni,

Monash University, Australia

Reviewed by:

Rafael A. Caparros-Gonzalez, University of Granada, Spain

Sonia Shenoy,

Manipal Academy of Higher Education, India

*Correspondence:

Zaneta M. Thaye

Zaneta.Marie.Thayer@dartmouth.edu

Specialty section:

This article was submitted to

Women's Mental Health,

a section of the journal

Frontiers in Global Women's Health

Received: 08 December 2020 Accepted: 22 March 2021

Published: 21 April 2021

Citation:

Sherin M, Gildner TE and Thayer ZM (2021) COVID-19-Related Changes to

Pregnant People's Work-Plans Increase Prenatal Depression.

Front. Glob. Womens Health

2:639429.

doi: $10.3389 /$ fgwh.2021.639429

\section{COVID-19-Related Changes to Pregnant People's Work-Plans Increase Prenatal Depression}

\author{
Margaret Sherin ${ }^{1}$, Theresa E. Gildner ${ }^{2,3}$ and Zaneta M. Thayer ${ }^{2 \star}$ \\ ${ }^{1}$ Geisel School of Medicine, Dartmouth College, Hanover, NH, United States, ${ }^{2}$ Department of Anthropology, Dartmouth \\ College, Hanover, NH, United States, ${ }^{3}$ Department of Anthropology, Washington University in St. Louis, St. Louis, MO, \\ United States
}

The COVID-19 pandemic has caused unprecedented rates of unemployment in the United States. Pregnant workers may be especially affected as they are over-represented in low-wage service and hospitality industries impacted by the pandemic. We surveyed an online convenience sample of currently working pregnant people living in the U.S. ( $n=1,417)$ to determine whether COVID-19-related changes to how long individuals planned to work during their pregnancy, and uncertainty about these changes, were associated with prenatal depression. As hypothesized, both COVID-19-related work-plan changes $(\mathrm{OR}=1.81,95 \% \mathrm{Cl} 1.36-2.42, p<0.001)$ and uncertainty about the precise nature of these changes $(\mathrm{OR}=2.62,95 \% \mathrm{Cl} 1.14-6.0, p=0.022)$ were associated with significantly higher odds of a clinically-significant depression score. These effects appeared to be even greater among individuals who continued working outside the home during the pandemic. Since the U.S. is one of the few countries in the world that does not guarantee paid parental leave, pregnant people may be forced to choose between keeping their jobs and risking infection during the COVID-19 pandemic. Our results demonstrate a need for immediate suspension of the eligibility requirements for the Family and Medical Leave Act and/or universal access to both paid family leave and prenatal depression screening. This would help to alleviate these concerns and provide pregnant people with more options while preserving their employment status and financial security.

Keywords: Coronavirus, pregnant workers, perinatal depression screening, paid family leave, Family and Medical Leave Act

\section{INTRODUCTION}

The COVID-19 pandemic has drastically affected employment in the U.S., with national unemployment rates hovering around $6.7 \%$ as of December 2020 after reaching a high of $14.7 \%$ in April $2020(1,2)$. Women, especially those that are pregnant, are over-represented in low-wage industries impacted by the pandemic (e.g., service and hospitality), leaving them vulnerable to changes in their work-plans during their pregnancy (3-5). Moreover, the three most common jobs held by pregnant women (elementary school teachers, nurses, and home health aides) put them at significant risk for infection (3). In the absence of universal paid parental leave and strict eligibility requirements for the federal 1993 Family and Medical Leave Act (FMLA), pregnant persons working outside the home may be forced to choose between keeping their job and risking infection (6-10), leading them to feel like they have little control over their circumstances. 
Perceived lack of control over life events can substantially impact mental health, increasing depression risk (11-14). For example, pregnant individuals reporting a low sense of control over triggers such as stressful life events and lower income have been found to have a higher likelihood of perinatal depression (15). It is therefore reasonable to expect that unplanned alterations to work-plans and uncertainty about the nature of these changes due to the COVID-19 pandemic may elevate depression risk among pregnant persons. However, this has yet to be fully explored, despite the fact that pregnant people display elevated depression risk. Depression during and after pregnancy is more common than in the general population, affecting one in seven women in high-income countries (15). This may be due to higher rates of depression in women than men in general, as well as increased life demands and hormonal changes during pregnancy and the postpartum period.

Even still, perinatal depression is often underreported due to stigma $(15,16)$ and a failure of health care providers to screen pregnant people for depression (17). The CDC reports that about one in five pregnant people are not asked about depression symptoms during a prenatal visit (17). Recent evidence suggests that perinatal depression symptomatology has become even more common during the COVID-19 pandemic (18-20). These changes appear to be linked with factors including disruptions to daily exercise routines, social isolation, financial stress, and fears of COVID-19's impact on mothers and their infants' long-term health, highlighting the need for increased perinatal depression screening and treatment (18-22). Given the high percentage of individuals with prenatal depression who go undiagnosed and untreated, there is a need to improve depression screening and identify risk factors, especially during the COVID-19 pandemic.

Considering this background, the present study assesses whether changes and uncertainty surrounding work-plans during the COVID-19 pandemic significantly predict the likelihood of prenatal depression among pregnant persons living in the U.S. Specifically, we examined whether pandemic-related changes to how long individuals intended to work during their pregnancy were associated with prenatal depression. We also examined whether uncertainty about changes to workplans was associated with prenatal depression. We hypothesized that currently working individuals reporting changes to how long they planned to work in pregnancy or uncertainty about their work-plans during the COVID-19 pandemic would have significantly higher depression scores. Information on the effects of the COVID-19 pandemic on pregnant people's workplans and associated depression risk can help guide both the development of comprehensive national policies on paid parental leave, and universal screening and referral protocols for perinatal depression.

\section{MATERIALS AND METHODS}

Data come from the COVID-19 and Reproductive Effects (CARE) study, an online survey that was administered to a convenience sample recruited primarily through social media (i.e., Twitter and Facebook) and via dissemination to U.S.-based contacts working in maternal health. Surveys were completed between April 16th-30th 2020. The target population for the CARE study was pregnant people aged 18 years or older living in the United States, while the present analysis focuses specifically on those participants who were working at the time of survey completion. This study received ethical approval from Dartmouth College (STUDY00032045). Informed consent was collected by participants clicking a box saying that they consent to the information provided on the consent form. The survey was administered in REDCap, which automatically captures survey responses.

Completion of the survey was voluntary, and participants were allowed to skip any questions they did not want to answer. Only individuals who completed the survey (went through to the end of the questionnaire, even if they were missing data on individual questions) were included in the analysis. Of 2,467 people who consented to take the survey, 1,970 completed it (80\%). Of the complete surveys, 1,600 participants were currently working and therefore eligible for inclusion in these analyses.

\section{COVID-19 Pandemic Effects on Work-Plans}

Participants were asked "Has the pandemic changed your plans for how long you plan to work during your pregnancy?” (yes/no).

\section{Work-Plan Uncertainty}

If participants reported that COVID-19 had changed their workplans, they were prompted to qualitatively describe how their work-plans had been affected. A subset of 348 participants provided a qualitative response describing these changes. Given that work-plan uncertainty has been linked with increased emotional distress (23), these 348 qualitative responses were assessed to identify participants who were uncertain about the precise nature of changes to work-plans (e.g., whether or not they would stop working earlier than planned due to fear of getting COVID-19 or an inability to continue working entirely from home).

\section{Work Location}

Participants who reported that they were currently working were asked to identify their work location (from home; outside the home; or both).

\section{Depression Symptoms}

Depression symptoms were screened for using the Edinburgh Postnatal Depression Survey (EPDS) (24). The EPDS is considered to be the gold standard perinatal depression measure and is the most widely used validated screening tool worldwide [e.g., $(25,26)]$. Depression symptoms were analyzed according to clinically significant prenatal depression criteria for pregnant persons (cut point $\geq 15$ ) (27).

\section{Age}

Participants self-reported their age in years.

\section{Education}

Participants selected their highest completed education from the following options: Some high school, no diploma (1) High school graduate, diploma or the equivalent (for example: GED) 
(2) Some college credit, no degree (3) Trade/technical/vocational training (4) Associate degree (5) Bachelor's degree (6) Master's degree (7) Professional degree (8) Doctorate degree (9). A composite education variable was created for analysis: less than a bachelor's degree, a bachelor's degree, or a degree beyond a bachelor's degree.

\section{Household Income}

Participants indicated their annual household income (USD) from the following options: $<\$ 10,000$ (1); $\$ 10,000-19,999$ (2); $\$ 20,000-34,999$ (3); $\$ 35,000-49,999$ (4); $\$ 50,000-74,999$ (5); $\$ 75,000-99,999$ (6); $\$ 100,000+(7)$. A composite household income variable was created for analysis: $<\$ 49,999, \$ 50,000$ 99,999 , and $\$ 100,000+$.

\section{Race/Ethnicity}

Race/ethnicity were self-reported and measured according to the Office of Management and Budget Standards (28). Native Hawaiian/Pacific Islander participants were re-classified as "Other" due to a small sample size $(N=3)$.

\section{Current Gestational Week}

Participants indicated their current gestational week.

\section{High-Risk Pregnancy}

Participants were categorized as high risk if they reported that they had been classified as "high-risk" by their maternity care provider or if they were aged 35 or older.

\section{Self-Reported Health}

Participants were asked whether they would describe their health as poor, fair, good, or excellent. This was re-categorized into good/excellent vs. poor/fair.

\section{Statistical Analysis}

Data analyses were conducted using Stata 15.1. All continuous variables exhibited normal distributions, with skewness values within $\sim \pm 0.5$ and kurtosis values within $\sim \pm 3$. Multicollinearity was not detected between any variables; all VIF values were in an acceptable range of 1.03-1.75. Sample descriptive statistics were calculated and bivariate analyses were conducted to evaluate significant differences in study covariates according to COVID19-associated work-plan changes.

A multivariate logistic regression was used to evaluate whether work-plan changes predicted a clinically significant depression score (EPDS $\geq 15$; yes/no). The model was adjusted for maternal age, education, income, week of pregnancy at time of survey, self-rated health, race/ethnicity, working outside the home, and "high-risk" pregnancy. After analyzing this relationship in the entire sample, we then stratified the analysis according to whether participants were working entirely from home during the pandemic or working outside the home. We then repeated this analysis process (i.e., multivariate logistic regression including the same covariates within the complete sample, and then stratified by work location) to evaluate whether there was an association between depression and work-plan uncertainty.

\section{RESULTS}

In total, 1,417 participants were eligible for the study (i.e., reported they were currently working) and were not missing data for study variables and were therefore included in the analysis. Study participants were a mean of 31.7 years old $(\mathrm{SD}=4.2)$ and 25.8 weeks pregnant $(\mathrm{SD}=8.8)$ at the time of survey completion. The study sample was $87.0 \%$ White $(N=1223)$, $5.6 \%$ Hispanic/Latina $(N=79), 1.6 \%$ African American $(N=$ 23), 3.5\% Asian $(N=49), 0.6 \%$ American Indian/Alaskan Native $(N=8)$, and $1.8 \%$ Other $(N=25)$. Over one-third $(34.7 \%, N$ $=491$ ) of the study population had a college education, and nearly one-half $(49.4 \%, N=700)$ of the study population had a degree beyond a college education. When asked about household income, $8.2 \%$ of respondents $(N=116)$ reported earning $<\$ 49,999$ annually, 34.7\% $(N=491)$ reported earning between $\$ 50-99,000$, and 61.6\% $(N=873)$ reported earning $\$ 100,000+$ (Table 1). Moreover, $26.2 \%$ of study participants $(N=372)$ reported that they experienced a COVID-19-related work-plan change (Table 1). Additionally, among the 348 participants who described how their work-plans had been altered by COVID-19, 30 individuals explicitly stated that they were uncertain how the pandemic would alter their work-plans.

In bivariate analyses, participants who experienced a COVID19-related work-plan change reported lower household incomes $\left[\chi_{(2)}^{2}=17.70, p<0.001\right]$, were less educated $\left[\chi_{(2)}^{2}=9.62\right.$, $p=0.008]$, were farther along in pregnancy $\left[\mathrm{t}_{(1415)}=-4.57\right.$, $p<0.001)$, and were more likely to continue to work outside the home during COVID-19 $\left[\chi_{(2)}^{2}=52.41, p<0.001\right]$ compared to individuals who did not experience a COVID-19-related workplan change. There were no statistically significant differences in maternal age $\left[\mathrm{t}_{(1415)}=1.66, p=0.10\right]$, race/ethnicity $\chi_{(5)}^{2}=$ 6.37, $p=0.27$ ], high-risk pregnancy $\left[\chi_{(1)}^{2}=0.36, p=0.55\right]$, previous birth $\left[\chi_{(1)}^{2}=0.002, p=0.96\right]$, self-rated health $\left[\chi_{(1)}^{2}=\right.$ $0.59, p=0.44]$ or provider type $\left[\chi_{(2)}^{2}=0.51, p=0.76\right]$ between individuals reporting a work-plan change and those reporting no change (Table 1).

Participants who experienced a COVID-19-related workplan change had a significantly higher mean EPDS score (12.0) compared to individuals who did not report a COVID-19-related work-plan change $\left[\mathrm{EPDS}=9.9 ; \mathrm{t}_{(1415)}=-6.81, p<0.001\right]$. In multivariate logistic regression models using an EPDS score $\geq 15$ as the clinical cutoff for depression and adjusting for covariates, participants reporting a work-plan change were significantly more likely to exhibit a depression score above the clinical cutoff point compared to those reporting no work-plan change $(\mathrm{OR}=$ $1.81,95 \%$ CI $1.36-2.42, p<0.001$, Table 2 ). When stratifying the sample according to whether participants worked entirely from home or outside the home, work-plan change was significantly associated with an increased likelihood of depression in both models, but the OR appeared larger for those working outside the home (working outside the home: $\mathrm{OR}=2.39,95 \% \mathrm{CI}=1.42-$ $4.05, p=0.001$; working from home only: $\mathrm{OR}=1.61,95 \% \mathrm{CI}$ $1.13-2.29, p=0.007$, Figure 1).

Likewise, uncertainty about the nature of the work-plan change was significantly associated with an increased likelihood 
TABLE 1 | Descriptive statistics.

\begin{tabular}{|c|c|c|c|c|}
\hline & Total sample $(N=1,417)$ & $\begin{array}{l}\text { COVID-19 related change in } \\
\text { work-plans }(N=372)\end{array}$ & $\begin{array}{l}\text { No COVID-19 related change } \\
\text { in work-plans }(N=1,045)\end{array}$ & $p$-value* \\
\hline Age & $31.7(4.2)$ & $31.3(4.1)$ & $31.8(4.2)$ & 0.10 \\
\hline Weeks pregnant & $25.8(8.8)$ & $27.6(8.2)$ & $25.2(9.0)$ & $<0.001$ \\
\hline Race/ethnicity & & & & 0.27 \\
\hline White & 1,233 (87.0\%) & 322 (86.6\%) & 911 (87.2\%) & \\
\hline Hispanic/Latino & 79 (5.6\%) & $25(6.7 \%)$ & $54(5.2 \%)$ & \\
\hline African American & $23(1.6 \%)$ & $2(0.5 \%)$ & $21(2.0 \%)$ & \\
\hline Asian & $49(3.5 \%)$ & $15(4.0 \%)$ & $34(3.3 \%)$ & \\
\hline $\begin{array}{l}\text { American Indian/Alaska } \\
\text { Native }\end{array}$ & $8(0.6 \%)$ & $3(0.8 \%)$ & $5(0.5 \%)$ & \\
\hline Other & $25(1.8 \%)$ & 5 (1.3\%) & $20(1.9 \%)$ & \\
\hline Household Income & & & & $<0.001$ \\
\hline$<49,999$ & $116(8.2 \%)$ & 48 (12.9\%) & 68 (6.5\%) & \\
\hline$\$ 50-99,000$ & 428 (30.2\%) & $119(32.0 \%)$ & 309 (29.6\%) & \\
\hline$\$ 100,000+$ & $873(61.6 \%)$ & 205 (55.1\%) & 668 (63.9\%) & \\
\hline Education & & & & 0.008 \\
\hline $\begin{array}{l}\text { Less than a college } \\
\text { education }\end{array}$ & 226 (16.0\%) & 78 (21.0\%) & $148(14.2 \%)$ & \\
\hline College education & $491(34.7 \%)$ & $124(33.3 \%)$ & 367 (35.1\%) & \\
\hline $\begin{array}{l}\text { Degree beyond College } \\
\text { education }\end{array}$ & 700 (49.4\%) & 170 (45.7\%) & 530 (50.7\%) & \\
\hline Self-rated health & & & & 0.44 \\
\hline Poor/Fair & $91(6.4 \%)$ & 27 (7.3\%) & $64(6.1 \%)$ & \\
\hline Good/Excellent & 1,326 (93.6\%) & 345 (92.7\%) & 981 (93.9\%) & \\
\hline High-risk pregnancy & 498 (35.1\%) & $126(33.9 \%)$ & $372(35.6 \%)$ & 0.55 \\
\hline Previous birth & 608 (42.9\%) & $160(43.0 \%)$ & 448 (42.9\%) & 0.96 \\
\hline Provider type & & & & 0.78 \\
\hline Obstetrician & 1,148 (81.0\%) & $306(82.3 \%)$ & $842(80.6 \%)$ & \\
\hline Midwife & 244 (17.2\%) & $60(16.1 \%)$ & $184(17.6 \%)$ & \\
\hline Other & $25(1.8 \%)$ & $6(1.6 \%)$ & $19(1.8 \%)$ & \\
\hline Current work location & & & & $<0.001$ \\
\hline Home & 1,039 (73.3\%) & 226 (60.8\%) & $813(77.8 \%)$ & \\
\hline Outside home & $286(20.2 \%)$ & $123(33.0 \%)$ & 163 (15.6\%) & \\
\hline $\begin{array}{l}\text { Both in the home/outside } \\
\text { the home }\end{array}$ & 92 (6.5\%) & $23(6.2 \%)$ & 69 (6.6\%) & \\
\hline $\begin{array}{l}\text { Depression symptoms } \\
\text { (EPDS, 0-30) }\end{array}$ & $10.5(5.2)$ & $12.0(5.1)$ & $9.9(5.1)$ & $<0.001$ \\
\hline
\end{tabular}

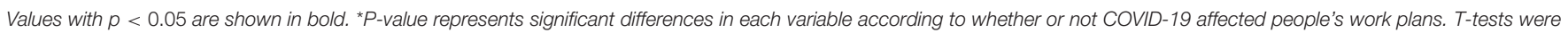
used for continuous variables, chi-squared tests for categorical variables.

Mean (SD) reported for continuous variables, $N$ (\%) for categorical variables.

of having a depression score above the clinical cutoff point $(\mathrm{OR}=$ $2.62,95 \%$ CI $1.15-6.0, p=0.022$, Table 2). When stratifying the sample according to whether participants worked entirely from home or outside the home, the coefficients were similar to or greater than that for the total sample but were no long statistically significant (working outside the home: $\mathrm{OR}=3.02,95 \% \mathrm{CI}=$ $0.73-12.6, p=0.13$; working entirely from home: $\mathrm{OR}=2.33$, $95 \% \mathrm{CI}=0.78-6.92, p=0.13$ ) (Figure 2). This non-significant finding may be due to reduced statistical power resulting from only a subset of the sample reporting on the exact nature of work-plan changes. Self-rated health was the only covariate that was significantly associated with depression in adjusted models; respondents who reported good/excellent health had a lower likelihood of depression regardless of work-plan changes (Model 1: OR $=0.29,95 \%$ CI 0.19-0.47, $p<0.001$ ) (Table 2).

\section{DISCUSSION}

The aim of our study was to examine whether COVID-19related changes to how long pregnant people intended to work during their pregnancy were associated with prenatal depression. Pregnant people who reported that COVID-19 had affected how long they planned to work during pregnancy 
TABLE 2 | Regression results for association between work-plan changes and clinically significant depression (Model 1) and uncertainty about work-plan changes and depression (Model 2).

\begin{tabular}{|c|c|c|}
\hline & $\begin{array}{c}\text { Model } 1(N=1,417) \\
\text { OR }(95 \% \mathrm{Cl})\end{array}$ & $\begin{array}{c}\text { Model } 2(N=348) \\
\text { OR }(95 \% \mathrm{Cl})\end{array}$ \\
\hline Work-plan change & $1.81(1.36-2.42)^{\star}$ & - \\
\hline $\begin{array}{l}\text { Uncertainty about work-plan } \\
\text { change }\end{array}$ & - & $2.62(1.14-6.00)^{*}$ \\
\hline \multicolumn{3}{|l|}{ Provider type } \\
\hline Obstetrician & REF & REF \\
\hline Midwife & 0.98 (0.69-1.39) & $0.56(0.27-1.17)$ \\
\hline Other & $0.77(0.26-2.29)$ & $1.32(0.23-7.72)$ \\
\hline \multicolumn{3}{|l|}{ Race/ethnicity } \\
\hline White & REF & REF \\
\hline Hispanic/Latino & $1.43(0.86-2.40)$ & $0.94(0.35-2.48)$ \\
\hline African American & $1.14(0.40-3.20)$ & Omitted \\
\hline Asian & $0.27(0.09-0.79)^{*}$ & $0.59(0.15-2.31)$ \\
\hline $\begin{array}{l}\text { American Indian/Alaska } \\
\text { Native }\end{array}$ & $1.30(0.26-6.62)$ & $1.64(0.13-18.78)$ \\
\hline Other & $1.66(0.67-4.10)$ & $2.18(0.33-14.24)$ \\
\hline \multicolumn{3}{|l|}{ Income } \\
\hline$<49,999$ & REF & REF \\
\hline$\$ 50-99,000$ & $0.78(0.48-1.27)$ & 0.89 (0.39-2.02) \\
\hline$\$ 100,000+$ & $0.72(0.44-1.17)$ & $1.04(0.45-2.38)$ \\
\hline \multicolumn{3}{|l|}{ Education } \\
\hline $\begin{array}{l}\text { Less than a college } \\
\text { education }\end{array}$ & REF & REF \\
\hline College education & $0.82(0.55-1.21)$ & $0.64(0.32-1.26)$ \\
\hline $\begin{array}{l}\text { Degree beyond college } \\
\text { education }\end{array}$ & $0.69(0.46-1.03)$ & $0.59(0.30-1.16)$ \\
\hline No previous birth & $0.93(0.71-1.22)$ & $0.90(0.53-1.53)$ \\
\hline High risk pregnancy & $1.05(0.76-1.46)$ & $1.08(0.59-7.95)$ \\
\hline Weeks pregnant & $1.00(0.98-1.01)$ & 0.99 (0.96-1.02) \\
\hline Maternal age & $0.98(0.94-1.02)$ & $0.97(0.90-1.05)$ \\
\hline \multicolumn{3}{|l|}{ Current health } \\
\hline Poor/Fair & REF & REF \\
\hline Good/Excellent & $0.29(0.19-0.47)^{\star}$ & $0.50(0.22-1.18)$ \\
\hline Adjusted model R2 & 0.05 & 0.04 \\
\hline
\end{tabular}

Values with $p<0.05$ are shown in bold. ${ }^{*} p<0.05$.

were significantly more likely to exhibit signs of clinical depression, as were individuals who were unsure how their work-plans would be affected by COVID-19. These effects appeared to be particularly strong among individuals who continued to work outside of the home during the pandemic. Cumulatively, our findings support the study hypotheses and are consistent with earlier work. Previous research conducted among working pregnant people living in the U.S. indicates that maintaining a sense of control bolsters mental health during the transition to parenthood (29). Keeton et al. also found that this protective sense of control includes perceived ability to manage work schedules (29). Likewise, reports of "serious difficulties at work" have been linked with prenatal depression risk (30). These findings and the results of the present study suggest that work disruptions may elevate maternal depression risk.
Pregnant workers are especially vulnerable to COVID-19related work disruptions. The three most common occupations for pregnant women are elementary school teachers, nurses, and home health aides, all of which have been considered essential during the COVID-19 pandemic and may put individuals at significant risk of contracting disease (3). Additionally, more than one in five pregnant workers are employed in low-wage jobs, which often have inflexible scheduling (impairing ability to attend doctor appointments) and generally lack paid sick leave or work-from-home options (3-5). These factors render pregnant workers in essential and low-wage positions more susceptible to contracting COVID-19 and thus increase their likelihood of having a work-plan change during the pandemic, either because they become sick or fear becoming sick.

Additionally, uncertainty surrounding future work-plans appears to be an important determinant of depression risk among 

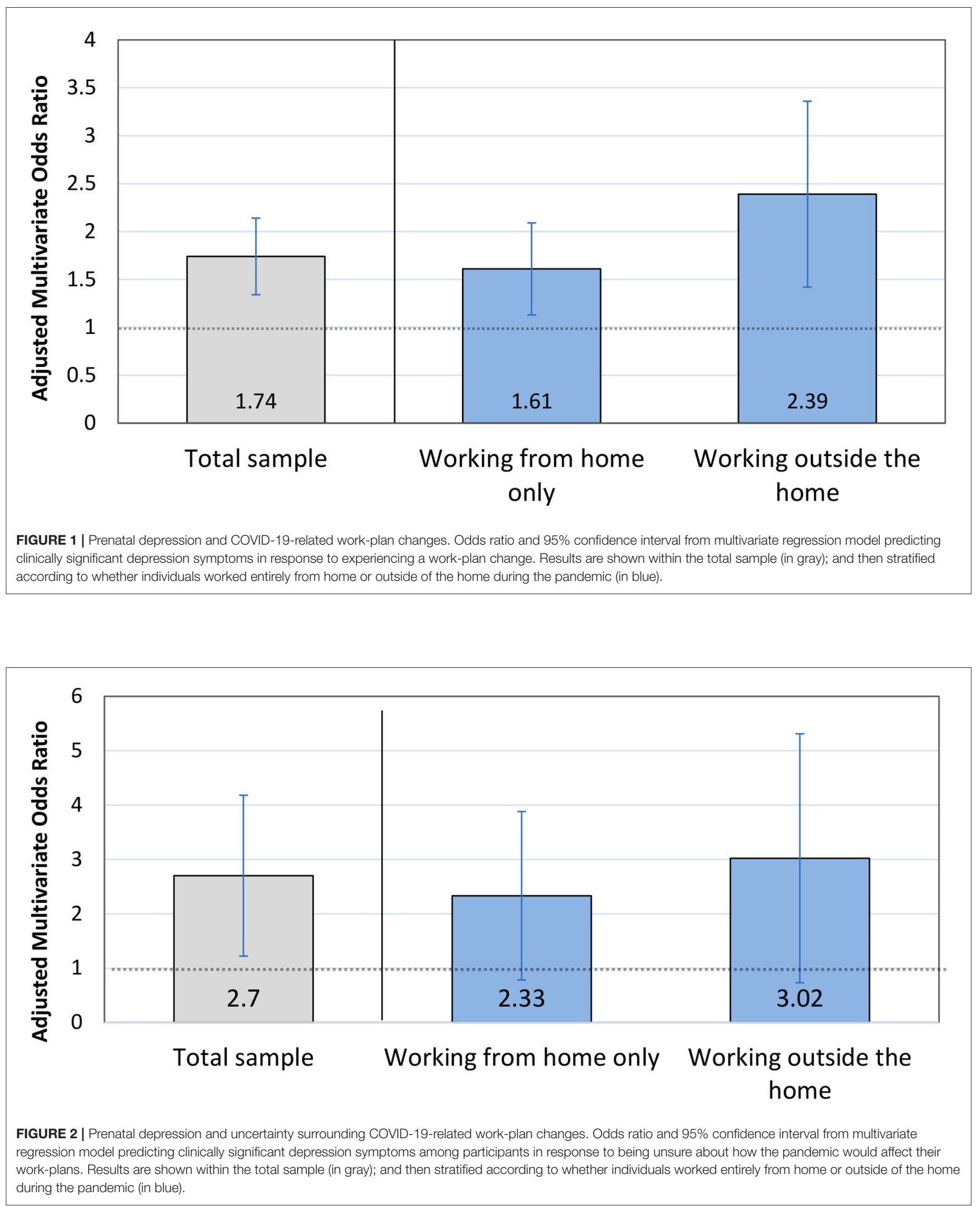
pregnant people, which is consistent with previous findings that perceived lack of control over life events is central to the development of depression $(12,14,15,31,32)$. Therefore, in response to rising perinatal depression rates during the pandemic, obstetric care providers can use the results from this analysis to better identify depression risk factors during COVID-19 and use this information to better screen patients. For instance, the results of our analysis suggest that clinicians should consider adding screening questions related to workplan disruptions (either resulting from COVID-19 or other factors), as they could signify a risk factor for depression. Moreover, clinicians and medical researchers should consider how uncertainty related to a range of factors-including workplans, financial situations, and even pregnancy outcomesmay impact maternal mental health. Documenting common sources of uncertainty may help healthcare providers and researchers design more effective interventions to address these underlying issues (e.g., offer targeted information and resources relevant to a particular source of uncertainty, thereby helping the affected individual regain some sense of control).

Unfortunately, even though mental health concerns are increasing during the pandemic, in-person clinical screens for depression have decreased as most prenatal appointments are done remotely by telehealth $(4,18-20,33)$. The American College of Obstetricians and Gynecologists recommends that obstetric care providers screen patients for depression and anxiety at least once during the perinatal period using a standardized, validated tool (15). Many studies $(4,34,35)$ have argued for obstetricians to go beyond this recommendation and make depression screening a routine part of prenatal care, as screening is critical to avoid adverse outcomes for mother and baby and to reduce postpartum depression risk, a leading cause of maternal mortality $(16,34-37)$.

One way to mediate the effects of COVID-19-related work-plan changes and prenatal depression would be through universal paid family leave, which could alleviate anxiety caused by choosing to work while risking infection (4). The U.S. is one of the few countries in the world that does not guarantee paid parental leave, despite the benefits associated with leave (e.g., reduced cesarean section rates and lower infant mortality) $(6,9)$. The FMLA gives workers 12 weeks of unpaid time off, but only $\sim 60 \%$ of workers are actually eligible (7, 9, 10). Employer provision of any paid family leave (PFL) is voluntary and more common among high-paying occupations; in 2018 , only $16 \%$ of employees had access to PFL $(7,8,10)$. Policy recommendations could therefore include instituting a universal paid family leave policy and/or temporarily suspending FMLA eligibility requirements (5). Future research can also investigate whether states and countries with more favorable parental leave policies have had better mental health outcomes during the COVID-19 pandemic relative to those without such policies.

Despite the strengths of this study, including the large sample size and wide distribution of participants across the U.S., our study was limited by the nature of self-reported data (38). Future work should test these associations using more objective measures designed to explicitly capture types of work-plan changes and the uncertainty surrounding these changes [e.g., providing a list of possible work-plan changes and asking participants to select the response(s) that accurately described their situation]. Additionally, as the survey was distributed through social media, it did not involve random sampling, despite attempts to distribute the survey to a diverse set of maternal-health organizations in various states. Our study population was less diverse than the U.S. birthing population, with study participants more likely to be nonHispanic White and to report higher education and income levels than national averages (39). Another limitation was that prenatal participant data were not available on social support received or relevant mental health history (e.g., current psychotropic treatment, previous depression diagnoses, or family history of mental illness), variables that have been linked with prenatal depression risk e.g., $(30,40)$. Finally, individuals with severe depression may have been less likely to complete the study survey.

Our analysis also only included currently working individuals, excluding anyone who stopped working before our study began. We focused on currently working participants to evaluate the relationship between work-plan changes and prenatal depression, since depression risk among individuals who had already stopped working could be impacted by changes in routine, financial stress (21), and other factors not directly related to anticipated work-plan changes. Additionally, while respondents qualitatively described working more or less during pregnancy due to the pandemic, this information was not systematically collected so was not included in the present analysis.

More research is needed to assess the effects of workplan changes and uncertainty during the COVID-19 pandemic in more diverse study populations, especially as Black and Latinx individuals are more likely to hold low-wage occupations affected by the pandemic (3). Moreover, populations who do not speak English or have reliable internet access may be particularly affected by the absence of in-person perinatal depression screens due to language and technology barriers (4). Longitudinal research is also needed to establish directionality in the relationship between COVID-19-related work-plan changes and depression.

Our study found that COVID-19-related work-plan changes and work-plan uncertainty were associated with depression, independent of risk factors including income and education. These results suggest a need for increased mental health screening during the pandemic by providers. Additionally, increased access to FMLA and universal PFL may help reduce stress both during and after the pandemic.

\section{DATA AVAILABILITY STATEMENT}

Study data are available from the corresponding author upon reasonable request. Requests can be made through the CARE study website (https://sites.dartmouth.edu/care2020/). 


\section{ETHICS STATEMENT}

This study received ethical approval from Dartmouth College (STUDY00032045). Study information (e.g., study summary, purpose, benefits, risks, and privacy protection details) was provided to all participants prior their completion of the survey. Informed consent was collected by asking potential participants to click a box saying that they had read the study information and consented to participating in the study.

\section{AUTHOR CONTRIBUTIONS}

MS: conceptualized and wrote the manuscript. TG and ZT: study design, revised, and wrote the manuscript. All authors contributed to the article and approved the submitted version.

\section{REFERENCES}

1. Bureau of Labor Statistics, U. S. Department of Labor, BLS. News Release: The Employment Situation. (2020). Available online at: https://www.bls.gov/news. release/pdf/empsit.pdf (accessed July 8, 2020).

2. Couch KA, Fairlie RW, Xu H. The impacts of COVID-19 on minority unemployment: first evidence from april 2020 CPS microdata. SSRN. (2020) 3604814. doi: 10.2139/ssrn.3604814

3. Harwood M, Heydemann S. By the Numbers: Where do Pregnant Women Work? National Women's Law Center (2019). Available online at: https://nwlc. org/wp-content/uploads/2019/08/Pregnant-Workers-by-the-Numbers-v31.pdf (accessed July 2, 2020).

4. Onwuzurike C, Meadows AR, Nour NM. Examining inequities associated with changes in obstetric and gynecologic care delivery during the Coronavirus Disease 2019 (COVID-19) Pandemic. Obstetr Gynecol. (2020) 136:37-41. doi: 10.1097/AOG.0000000000003933

5. Alon TM, Doepke M, Olmstead-Rumsey J, Tertilt M. The impact of COVID-19 on gender equality. Natl Bureau Econ Res. (2020) 1-37. doi: $10.3386 /$ w26947

6. Jay L. Divergent trends in US maternity and paternity leave, 1994-2015. Am J Public Health. (2017) 107:460-5. doi: 10.2105/AJPH.2016.303607

7. ACOG committee opinion No. 733 summary: employment considerations during pregnancy and the postpartum period. Obstet Gynecol. (2018) 131:7545. doi: 10.1097/AOG.0000000000002587

8. Donovan SA. Paid Family Leave in the United States. R44835. Washington DC: Congressional Research Service (2018).

9. Rubin R. Despite potential health benefits of maternity leave, US lags behind other industrialized countries. JAMA. (2016) 315:643-5. doi: 10.1001/jama.2015.18609

10. Jackson RA, Gardner S, Torres LN, Huchko MJ, Zlatnik MG, Williams JC. My obstetrician got me fired: how work notes can harm pregnant patients and what to do about it. Obstetr Gynecol. (2015) 126:250-4. doi: 10.1097/AOG.0000000000000971

11. Dijkstra M, Homan AC. Engaging in rather than disengaging from stress: effective coping and perceived control. Front Psychol. (2016) 21:1415. doi: 10.3389/fpsyg.2016.01415

12. Rubenstein LM, Alloy LB, Abramson LY. Perceived control and depression. Perceived Control. (2016) 50:229-52. doi: 10.1093/acprof:oso/9780190257040.003.0010

13. Brown TA, Naragon-Gainey K. Evaluation of the unique and specific contributions of dimensions of the triple vulnerability model to the prediction of DSM-IV anxiety and mood disorder constructs. Behav Therapy. (2013) 44:277-92. doi: 10.1016/j.beth.2012.11.002

14. Havranek MM, Bolliger B, Roos S, Pryce CR, Quednow BB, Seifritz E. Uncontrollable and unpredictable stress interacts with subclinical depression and anxiety scores in determining anxiety response. Stress. (2016) 19:53-62. doi: 10.3109/10253890.2015.11 17449

\section{FUNDING}

ZT was funded by the Wenner-Gren Hunt Fellowship (grant \#9687) during this project. Participant compensation was provided through the Claire Garber Goodman Fund in the Department of Anthropology at Dartmouth College.

\section{ACKNOWLEDGMENTS}

We want to express our gratitude to Nadia Clement, who assisted with building the online survey and designing the recruitment flyers, and Gloriuese Uwizeye, $\mathrm{PhD}$ and Chlöe Sweetman, MA who provided feedback on the questionnaire during development.
15. American College of Obstetricians and Gynecologists. ACOG Committee Opinion No. 757: screening for perinatal depression. Obstetr Gynecol. (2018) 132:e208-12. doi: 10.1097/AOG.0000000000002927

16. Kanes S, Colquhoun H, Gunduz-Bruce H, Raines S, Arnold R, Schacterle A, et al. Brexanolone (SAGE-547 injection) in post-partum depression: a randomised controlled trial. Lancet. (2017) 390:480-9. doi: 10.1016/S0140-6736(17)31264-3

17. Bauman BL, Ko JY, Cox S, D’Angelo DV, Warner L, Folger S, et al. Vital signs: postpartum depressive symptoms and provider discussions about perinatal depression-United States, 2018. Morbid Mortal Wkly Rep. (2020) 69:575. doi: 10.15585/mmwr.mm6919a2

18. Saccone G, Florio A, Aiello F, Venturella R, De Angelis MC, Locci M, et al. Psychological impact of COVID-19 in pregnant women. Am J Obstetr Gynecol. (2020) 223:293-5. doi: 10.1016/j.ajog.2020.05.003

19. Fakari FR, Simbar M. Coronavirus pandemic and worries during pregnancy; a letter to editor. Arch Acad Emerg Med. 8:e21-e21.

20. Davenport M, Meyer S, Meah VL, Strynadka MC, Khurana R. Moms are not OK: COVID-19 and maternal mental health. Front Global Womens Health. (2020) 1:1. doi: 10.3389/fgwh.2020.00001

21. Thayer ZM, Gildner TE. COVID-19-related financial stress associated with higher likelihood of depression among pregnant women living in the United States. Am J Hum Biol. (2020) e23508. doi: 10.1002/ajhb.23508

22. Gildner TE, Laugier EJ, Thayer ZM. Exercise routine change is associated with prenatal depression scores during the COVID-19 pandemic among pregnant women across the United States. PLoS ONE. (2020) 15:e243188. doi: 10.1371/journal.pone.0243188

23. Shihata S, McEvoy PM, Mullan BA, Carleton RN. Intolerance of uncertainty in emotional disorders: what uncertainties remain? J Anxiety Disord. (2016) 41:115-24. doi: 10.1016/j.janxdis.2016.05.001

24. Cox JL, Holden JM, Sagovsky R. Edinburgh postnatal depression scale (EPDS). Br J Psychiatry. (1987) 150:782-6. doi: 10.1192/bjp.150.6.782

25. Dennis CL. Psychosocial and psychological interventions for prevention of postnatal depression: systematic review. Bmj. (2005) 331:15. doi: $10.1136 / \mathrm{bmj} .331 .7507 .15$

26. Santos IS, Matijasevich A, Tavares BF, da Cruz Lima AC, Riegel RE, Lopes BC. Comparing validity of Edinburgh scale and SRQ20 in screening for post-partum depression. Clin Pract Epidemiol Mental Health. (2007) 1:8. doi: 10.1186/1745-0179-3-18

27. Matthey S, Henshaw C, Elliott S, Barnett B. Variability in use of cut-off scores and formats on the Edinburgh Postnatal Depression Scale-implications for clinical and research practice. Arch Womens Mental Health. (2006) 9:309-15. doi: 10.1007/s00737-006-0152-x

28. Office of Management and Budget. Revisions to the standards for the classification of federal data on race and ethnicity. Federal Regist. (1997) 62:58782-90.

29. Keeton CP, Perry-Jenkins M, Sayer AG. Sense of control predicts depressive and anxious symptoms across the transition to parenthood. J Fam Psychol. (2008) 22:212. doi: 10.1037/0893-3200.22.2.212 
30. Dayan J, Creveuil C, Dreyfus M, Herlicoviez M, Baleyte JM, O'Keane V. Developmental model of depression applied to prenatal depression: role of present and past life events, past emotional disorders and pregnancy stress. PLoS ONE. (2010) 5:e12942. doi: 10.1371/journal.pone.00 12942

31. McEvoy PM, Mahoney AE. To be sure, to be sure: Intolerance of uncertainty mediates symptoms of various anxiety disorders and depression. Behav Ther. (2012) 43:533-45. doi: 10.1016/j.beth.2011.02.007

32. Carleton RN, Mulvogue MK, Thibodeau MA, McCabe RE, Antony MM, Asmundson GJ. Increasingly certain about uncertainty: Intolerance of uncertainty across anxiety and depression. J Anxiety Disord. (2012) 26:468-79. doi: 10.1016/j.janxdis.2012.01.011

33. Boelig RC, Saccone G, Bellussi F, Berghella V. MFM guidance for COVID-19. Am J Obstetr Gynecol. (2020) 2:100106. doi: 10.1016/j.ajogmf.2020.100106

34. Goecke TW, Voigt F, Faschingbauer F, Spangler G, Beckmann MW, Beetz A. The association of prenatal attachment and perinatal factors with pre-and postpartum depression in first-time mothers. Arch Gynecol Obstetr. (2012) 286:309-16. doi: 10.1007/s00404-012-2286-6

35. Accortt EE, Cheadle AC, Schetter CD. Prenatal depression and adverse birth outcomes: an updated systematic review. Matern Child Health J. (2015) 19:1306-37. doi: 10.1007/s10995-014-1637-2

36. Jago CA, Singh SS, Moretti F. Coronavirus disease 2019 (COVID-19) and pregnancy. Obstetr Gynecol. (2020) 136:33-6. doi: 10.1097/AOG.0000000000003946
37. Robertson E, Grace S, Wallington T, Stewart DE. Antenatal risk factors for postpartum depression: a synthesis of recent literature. Gen Hosp Psychiatry. (2004) 26:289-95. doi: 10.1016/j.genhosppsych.2004. 02.006

38. Schneider S, May M, Stone AA. Careless responding in internetbased quality of life assessments. Qual Life Res. (2018) 27:1077-88. doi: 10.1007/s11136-017-1767-2

39. Martin J, Hamilton B, Osterman M, Driscoll A. Births: Final Data for 2018. Hyattsville, MD: National Center for Health Statistics (2019).

40. Biaggi A, Conroy S, Pawlby S, Pariante CM. Identifying the women at risk of antenatal anxiety and depression: a systematic review. J Affect Disord. (2016) 191:62-77. doi: 10.1016/j.jad.2015.11.014

Conflict of Interest: The authors declare that the research was conducted in the absence of any commercial or financial relationships that could be construed as a potential conflict of interest.

Copyright (c) 2021 Sherin, Gildner and Thayer. This is an open-access article distributed under the terms of the Creative Commons Attribution License (CC BY). The use, distribution or reproduction in other forums is permitted, provided the original author(s) and the copyright owner(s) are credited and that the original publication in this journal is cited, in accordance with accepted academic practice. No use, distribution or reproduction is permitted which does not comply with these terms. 